\title{
Risk factors for meconium stained amniotic fluid and its implications
}

\section{Ramya Sundaram*, Anuradha Murugesan}

Department of Obstetrics and Gynaecology, SRM Medical College, Kattankulathur, Kanchipuram, Tamilnadu, India

Received: 10 July 2016

Accepted: 16 July 2016

\section{*Correspondence:}

Dr. Ramya Sundaram,

E-mail: drramya79@yahoo.co.in

Copyright: () the author(s), publisher and licensee Medip Academy. This is an open-access article distributed under the terms of the Creative Commons Attribution Non-Commercial License, which permits unrestricted non-commercial use, distribution, and reproduction in any medium, provided the original work is properly cited.

\begin{abstract}
Background: Meconium staining of amniotic fluid (MSAF) has for long been considered to be a predictor of adverse fetal outcome and meconium aspiration syndrome (MAS), a major cause of perinatal morbidity and mortality. The aim of the study was to identify the risk factors, perinatal outcome in deliveries complicated by meconium stained amniotic fluid.

Methods: This study is a prospective case control study of 100 patients done in a tertiary care hospital over a period of six months. Fifty patients with meconium stained amniotic fluid detected at any time during the course of labour or prior to it were enrolled in the study group. The inclusion criteria for the study were, a singleton pregnancy, cephalic presentation, term gestation and absence of major congenital anomalies. For the control group, the next woman giving birth following the index patient who satisfied the same set of inclusion criteria and had clear amniotic fluid was selected. Data was collected on a standardized pretested proforma.

Results: Gestational age and parity showed no statistical significance between the study and control groups. Among antepartum and intrapartum risk factors, preeclampsia (32\% in the study group vs $6 \%$ in the control group) $\mathrm{p}=0.0034$, fetal growth restriction $(12 \%$ vs $2 \%) \mathrm{p}=0.05$, fetal distress $(36 \%$ vs $6 \%) \mathrm{p}=0.0002$ and labour dystocia $(20 \%$ vs none in the control group) $\mathrm{p}=0.0009$ were found to be statically significant. Caesarean section was considerably higher in patients with meconium stained amniotic fluid (66\% vs 28\%), p=0.0004. $3(66 \%)$ patients had thin meconium and 17 patients $(34 \%)$ had thick meconium stained amniotic fluid. Eighteen percent of the babies with meconium stained amniotic fluid had an Apgar of less than 7 at 5 minutes. Thirteen (26\%) of the babies with meconium stained amniotic fluid developed MAS.

Conclusions: Meconium stained amniotic fluid is associated with a higher incidence of operative deliveries resulting in an increased maternal morbidity. It is also associated with an increased neonatal morbidity due to birth asphyxia and respiratory depression at birth and a significant risk of neonatal mortality due to meconium aspiration syndrome.
\end{abstract}

Keywords: Meconium, Amniotic fluid, Apgar score, Meconium aspiration syndrome

\section{INTRODUCTION}

Meconium staining of amniotic fluid (MSAF) has for long been considered to be a predictor of adverse fetal outcome, and meconium aspiration syndrome, a major cause of perinatal morbidity and mortality. It has been associated with poor perinatal outcome including low apgar scores, increased rate of chorioamnionitis, increased incidence of neonatal intensive care admission and high rate of perinatal death. ${ }^{1}$ Globally, approximately
7-22\% of all live births are complicated by meconiumstained amniotic fluid. Meconium aspiration syndrome (MAS) occurs in 1-3\% of all cases of MSAF and in 10$30 \%$ of neonates, meconium is present below the vocal cords. $^{2}$

Meconium continues to be considered a soft marker of fetal distress, based on its historical role before modern perinatal management. Soft markers such as MSAF can be important in influencing obstetrical decisions and most 
obstetricians would confirm that the same situation is viewed differently in the presence of MSAF.

Predictors of MSAF provide a possible way of early identification of high risk cases and a possible way to reduce morbidity and mortality. Predictors can facilitate early referral and proper management. Remediable or preventable causes provide opportunities for intervention and planning.

This study aims to provide an up to date assessment of the true significance of MSAF and the meaning of its presence for the managing obstetrician, immediate postpartum fetal well-being and identification of probable risk factors for the development of MSAF.

\section{METHODS}

This study is a prospective case control study of 100 patients done in a tertiary care hospital over a period of six months. Fifty patients with meconium stained amniotic fluid detected at any time during the course of labour or prior to it were enrolled in the study group after obtaining an informed written consent in the vernacular language. The inclusion criteria for the study were: i) a singleton pregnancy, ii) cephalic presentation, iii) term gestation and iv) absence of major congenital anomalies. For the control group, the next woman giving birth following the index patient who satisfied the same set of inclusion criteria and had clear amniotic fluid was selected.

Data was collected on a standardized pretested proforma. Maternal age, parity, gestational age, antenatal care, antepartum complications like hypertension in pregnancy, anaemia, fetal growth restriction, oligohydramnios, induction/augmentation of labour with oxytocin, prostaglandin E1, prostaglandin E2, premature rupture of membranes, dystocia, chorioamnionitis, fetal distress, cord problems, type of meconium, mode of delivery, birth weight of baby, apgar scores at 1 and 5 minutes, development of meconium aspiration syndrome and neonatal death were recorded.

Statistical analysis of the study data was done with Microsoft excel XP 2010 (Microsoft, Seattle WA) on a personal computer. SAS software version 23 was used for statistical analysis. Comparison of proportions was done using chi-square test. Mean and standard deviations were calculated using standard methodologies. Stepwise logistic regression using univariate and multivariate analysis was used to determine the relative strengths of association.

\section{RESULTS}

The age of the patients in the study group ranged from 19-35 years. Gestational age and parity showed no statistical significance between the study and control groups (Table 1).
Table 1: Demographic characteristics.

\begin{tabular}{|c|c|c|c|}
\hline Parameters & $\begin{array}{l}\text { Cases } \\
(\mathbf{n}=50)\end{array}$ & $\begin{array}{l}\text { Control } \\
(n=50)\end{array}$ & p-value \\
\hline \multicolumn{4}{|l|}{ Age in years } \\
\hline$<18$ & $0(0 \%)$ & $192 \%)$ & \multirow{3}{*}{$>0.05$} \\
\hline $18-30$ & $42(84 \%)$ & $46(92 \%)$ & \\
\hline$>30$ & $8(16 \%)$ & $3(6 \%)$ & \\
\hline \multicolumn{4}{|l|}{ Gravida } \\
\hline Primigravida & $30(60 \%)$ & $23(46 \%)$ & \multirow{2}{*}{$>0.05$} \\
\hline Multigravida & $20(40 \%)$ & $27(54 \%)$ & \\
\hline $\begin{array}{l}\text { Mean gestational } \\
\text { age (weeks) }\end{array}$ & 38.88 & 38.83 & 0.7483 \\
\hline \multicolumn{4}{|l|}{ Antenatal care } \\
\hline Booked & $48(96 \%)$ & $44(88 \%)$ & \multirow{2}{*}{$>0.05$} \\
\hline Unbooked & $2(4 \%)$ & $6(12 \%)$ & \\
\hline
\end{tabular}

Table 2: Antepartum and intrapartum risk factors.

\begin{tabular}{|llll|}
\hline Risk factors & Cases & Controls & $\mathrm{p}$-value \\
\hline Preclampsia & $14(32 \%)$ & $3(6 \%)$ & 0.0034 \\
\hline Anaemia & $16(32 \%)$ & $12(24 \%)$ & $>0.05$ \\
\hline $\begin{array}{l}\text { Fetal growth } \\
\text { restriction }\end{array}$ & $6(12 \%)$ & $1(2 \%)$ & 0.05 \\
\hline Oligohydramnios & $45(90 \%)$ & $1(2 \%)$ & 0.092 \\
\hline Chorioamnionitis & $3(6 \%)$ & $0(0 \%)$ & 0.0786 \\
\hline $\begin{array}{l}\text { Premature rupture } \\
\text { of membranes }\end{array}$ & $12(24 \%)$ & $6(12 \%)$ & 0.1183 \\
\hline Fetal distress & $18(36 \%)$ & $3(6 \%)$ & 0.0002 \\
\hline Cord factors & $3(6 \%)$ & $0(0 \%)$ & 0.0786 \\
\hline Labour dystocia & $10(20 \%)$ & $0(0 \%)$ & 0.0009 \\
\hline
\end{tabular}

Table 3: Mode of delivery.

\begin{tabular}{|c|c|c|c|c|}
\hline \multirow{2}{*}{$\begin{array}{l}\text { Patient } \\
\text { groups }\end{array}$} & \multicolumn{4}{|c|}{ Mode of delivery } \\
\hline & Vaginal & Caesarean & Forceps & Vaccum \\
\hline $\begin{array}{l}\text { Study } \\
\text { group } \\
(n=50)\end{array}$ & $\begin{array}{l}15 \\
(30 \%)\end{array}$ & $\begin{array}{l}33 \\
(66 \%)\end{array}$ & $\begin{array}{l}1 \\
(1.67 \%)\end{array}$ & $\begin{array}{l}1 \\
(1.67 \%)\end{array}$ \\
\hline $\begin{array}{l}\text { Control } \\
\text { group } \\
(n=50)\end{array}$ & $\begin{array}{l}36 \\
(72 \%)\end{array}$ & $\begin{array}{l}14 \\
(28 \%)\end{array}$ & $\begin{array}{l}0 \\
(0 \%)\end{array}$ & $\begin{array}{l}0 \\
(0 \%)\end{array}$ \\
\hline
\end{tabular}

The incidence of preeclampsia in the total study population of 100 patients was 17 . Fourteen (32\%) of the patients with meconium stained amniotic fluid had been diagnosed with preeclampsia either in labour or antenatally. Only $3(6 \%)$ of the patients in the control group had preeclampsia. This difference was found to be highly statistically significant $(\mathrm{p}=0.0034)$ (Table 2$)$.

Anaemia, oligohydramnios and incidence of chorioamnionitis were not found to be statistically significant. In the study group, $6(12 \%)$ patients had the presence of fetal growth restriction in comparison to $1(2 \%)$ patient in the clear amniotic fluid group. This difference was statistically significant $(\mathrm{p}=0.05)$. A higher percentage of patients with induced labor pains had 
meconium stained amniotic fluid. This difference was also not statistically significant $(\mathrm{p}=0.0809)$ (Table 2).

Induction of labour with prostaglandin E1 and prostaglandin E2 did not have any effect on meconium staining of amniotic fluid but oxytocin use was significantly less in patients with meconium staining of amniotic fluid. $10(20 \%)$ patients in the study group had documented dystocia of labour versus none in the control group. This difference was found to be highly statistically significant. $(\mathrm{p}=0.0009)$ (Table 2).

Eighteen (36\%) patients with meconium stained amniotic fluid had documented fetal distress. Only $3(6 \%)$ patients with clear liquor had fetal distress. This difference in the frequency of fetal distress was highly statistically significant $(p=0.0002)$ showing the strong association of fetal distress and meconium stained amniotic fluid (Table 2).

Table 4: Apgar score.

\begin{tabular}{|lll|l|}
\hline Apgar score & Cases & Control & p-value \\
\hline$<7$ in one minute & $18(36 \%)$ & $3(6 \%)$ & 0.0002 \\
\hline$<7$ in five minutes & $9(18 \%)$ & $0(0 \%)$ & 0.0017 \\
\hline
\end{tabular}

Caesarean section rate was considerably higher in patients with meconium stained amniotic fluid (66\%). This difference was also highly statistically significant $(p=0.0004)$. This indicates that meconium stained amniotic fluid is associated with an increased maternal morbidity. $3(66 \%)$ patients had thin meconium and 17 $(34 \%)$ had thick meconium stained amniotic fluid (Table 3).

There were more numbers of babies (18\%) in the meconium stained amniotic fluid group that were depressed at birth. This difference was highly statistically significant. Thirteen (26\%) of the babies with meconium stained amniotic fluid developed MAS. One patient with thin MSAF developed MAS while 12 of the babies with MAS had been delivered through thick meconium stained amniotic fluid. This difference was statistically significant ( $\mathrm{p}=0.0199)$ (Table 4).

\section{DISCUSSION}

The incidence of MSAF during the study period was $9.45 \%$ in our institution. $84 \%$ of patients belonged to the 18-30 age group. In the study conducted by Naveen et al, maternal age $>30$ years was found to be a significant predictor for thick MSAF but maternal age was not associated with meconium stained amniotic fluid in present study. ${ }^{3}$ Greenwood et al found meconium passage more commonly with increasing gestation. ${ }^{4}$ Gestational age was found to be a significant factor with respect to meconium stained amniotic fluid in the studies conducted by Becker et al, Mundra et al, Naveen et al and Desai et al. ${ }^{3,5-7}$ In present study, $28 \%$ of the patients with meconium stained amniotic fluid had pregnancies beyond
40 weeks gestation compared to $16 \%$ in the control group. The difference in proportion of post-dated pregnancies was not found to be significant.

Higher rate of pregnancy induced hypertension among meconium stained liquor patients was found in the studies by Khan et al and Mundra et al. ${ }^{6,8}$ Preeclampsia was found in $32 \%$ of the patients with meconium stained amniotic fluid in present study. This was a significant $(\mathrm{p}=0.0034)$ risk factor for the presence of meconium stained amniotic fluid in the study.

Naveen et al identified fetal growth retardation as an independent risk factor for meconium stained amniotic fluid $(\mathrm{p}=0.01){ }^{3}$ Fetal growth restriction was found in $12 \%$ of the patients with meconium stained amniotic fluid in present study. It was found to be a significant risk factor for the presence of MSAF ( $\mathrm{p}=0.05)$ in this study. Jazayeri et al concluded from their study that meconium passage increases the risk of postpartum endometritis but is not associated with chorioamnionitis. ${ }^{9}$ Contrary to this, Tran et al found thick MSAF to be significantly associated with chorioamnionitis as compared to clear amniotic fluid. ${ }^{10}$ Chorioamnionitis was not found to be a significant factor associated with the presence of meconium stained amniotic fluid in this study.

There was no statistically significant difference found between spontaneous and induced labour with reference to the presence of meconium stained amniotic fluid. Greenwood et al reported similar findings in their study on the associations of the intrapartum passage of meconium. ${ }^{4}$

Naveen et al found prolonged labour to be a significant risk factor for meconium stained amniotic fluid $(\mathrm{p}=0.002) .{ }^{3}$ In present study $20 \%$ patients with meconium stained amniotic fluid had dystocia of labor. Labour dystocia was found to be a highly statistically significant factor with respect to meconium stained amniotic fluid $(p=0.0009)$. Gupta et al reported MSAF to be significantly more frequent in pregnancies with fetal distress $(p<0.001) .{ }^{11}$ Present study also found a strong association between fetal distress and meconium stained amniotic fluid $(\mathrm{p}=0.0002)$.

Becker et al reported the incidence of vaginal operative and caesarean section deliveries to be higher in the MSAF group $(p<0.01) .^{5}$ The incidence of operative interventions was significantly higher in the patients with meconium stained amniotic fluid $(\mathrm{p}=0.0004)$ in present study. Specifically, caesarean sections were significantly more frequent $(\mathrm{p}<0.0001)$ in patients with meconium stained amniotic fluid. $20 \%$ of babies with meconium stained amniotic fluid had low Apgar scores in the study done by Mundra et al. ${ }^{6}$ Eighteen percent $(p=0.0002)$ of the babies with meconium stained amniotic fluid had an Apgar of less than 7 at 5 minutes in current study. MAS developed in $28.4 \%$ cases of MSAF and it was associated with thick meconium in $87.32 \%$ in the study done by 
Bhatia $\mathrm{P}$ et $\mathrm{al}^{2}$ Meconium aspiration syndrome more frequently occurred in babies born to mothers with thick meconium. There were 3 neonatal deaths in present study population, all of whom belonged to the meconium stained amniotic fluid group, specifically thick meconium. The mortality due to MAS in the study was $7.6 \%$. This was comparable to the perinatal death rate of $7.7 \%$ in the MAS group reported by Usta et $\mathrm{al}^{12}$. Perinatal death was $9.2 \%$ in the study done by Bhatia et $\mathrm{al}^{2}$.

\section{CONCLUSION}

It was found that preeclampsia, fetal growth restriction and fetal distress were independently associated with an increased risk for meconium stained amniotic fluid in term pregnancies in our study. The identification of the presence of the risk factors should alert the obstetrician to anticipate the occurrence of meconium stained amniotic fluid. This would help in explaining the risks involved in such pregnancies to the mothers including, the risk of operative delivery, of meconium aspiration syndrome, of nursery care and finally the risk of neonatal mortality. It would also allow health care providers in the primary health care set up to make important decisions regarding referring the mothers to higher centres.

Funding: No funding sources Conflict of interest: None declared

Ethical approval: The study was approved by the Institutional Ethics Committee

\section{REFERENCES}

1. Ahanya SN, Lakshmanan J, Morgan BL, Ross MG. Meconium passage in utero: mechanisms, consequences and management. Obstet Gynecol Surv. 2005;60:45-56.

2. Bhatia P, Ela N. Fetal and neonatal outcome of babies in meconium stained amniotic fluid and meconium aspiration syndrome. J Obstet Gynecol India. 2007;57:501-4.
3. Naveen S, Sharma VK, Sarin R. Predictors of meconium stained amniotic fluid: a possible strategy to reduce neonatal morbidity and mortality. J Obstet Gynecol India. 2006;56:514-7.

4. Greenwood C, Lalchandani S, Macquillan K. Meconium passed in labour: how reassuring is clear amniotic fluid. Obstet Gynecol. 2003;102(1):89-93.

5. Becker S, Solomayer E, Doganet C. Meconiumstained amniotic fluid-perinatal outcome and obstetrical management in a low risk suburban population. Eur J Obstet Gynecol Reprod Biol. 2007;132:46-50.

6. Mundhra R, Agarwal M. Fetal outcome in meconium stained deliveries. J Clin Diagn Res. 2013;7(12):2874-6.

7. Desai D, Chauhan K, Chaudhary S. A study of meconium stained amniotic fluid, its significance and early maternal and neonatal outcome. Int J Reprod Contracept Obstet Gynecol. 2013;2:190-3.

8. Khatun M, Arzu J, Haque E, Kamal MAL, Mamun M, Khan M, et al. Fetal outcome in deliveries with meconium stained liquor. Bangladesh J Child Health. 2009;33:41-5.

9. Jazayeri A, Jazayeri MK, Sahinler $M$ et al. Is meconium passage a risk factor for maternal infection in term pregnancies. Obstet Gynecol. 2002;99:548-52.

10. Tran SH, Caughey AB, Musci TJ. Meconium-stained amniotic fluid is associated with puerperal infections. Am J Obstet Gynecol. 2003;189:746-50.

11. Gupta V, Bhatia BD, Mishra OP. Meconium stained amniotic fluid: antenatal, intrapartum and neonatal attributes. Indian Pedia. 1996;33(4):293-7.

12. Usta IM, Mercer BM, Sibai BM. Risk factors for meconium aspiration syndrome. Obstet Gynecol. $1995 ; 86(2): 230-4$.

Cite this article as: Sundaram R, Murugesan A. Risk factors for meconium stained amniotic fluid and its implications. Int J Reprod Contracept Obstet Gynecol 2016;5:2503-6. 